\title{
Effect of acid infusion into various levels of the intestine on gastric and pancreatic secretion in the cat
}

\author{
S. J. KONTUREK, J. DUBIEL, AND B. GABRYS \\ From the Department of Medicine, Medical School, Krakow, Poland
}

SUMMARY Intraduodenal infusion of increasing amounts of hydrochloric acid solution results in a stepwise increase in the volume of pancreatic secretion and output of bicarbonate, reaching about $90 \%$ of amounts attained with exogenous secretin infused intravenously in increasing doses.

Acid infusion into the different regions of the intestine stimulates pancreatic secretion only from the duodenum and upper jejunum, suggesting that the area of endogenous release of secretin by acid is confined to the upper part of the small bowel in the cat.

Gastric acid secretion induced by pentagastrin, but not by histamine, is inhibited by acid perfusion of the duodenum. The acidification of other parts of the small intestine does not result in any change in gastric acid secretion induced either by pentagastrin or by histamine.

Previous studies have shown that acidification of the duodenum in the cat inhibits gastric acid secretion and stimulates pancreatic secretion, due to the endogenous release of secretin (Konturek, Dubiel, and Gabryś, 1969; Konturek, Gabryś, and Dubiel, 1969). No study, however, has compared the relative effects on gastric and pancreatic secretion of acid infusions into various regions of the small intestine. This report is an attempt to localize the extent to which secretin is released by acid irrigation of different levels of the intestine in cats with chronic gastric and pancreatic fistulas.

\section{METHOD}

SURGICAL PROCEDURE The study was performed on five cats weighing 2.5 to $3.0 \mathrm{~kg}$, prepared with gastric fistulas according to the method previously described (Konturek and Król, 1966), and pancreatic fistulas using a Thomas-type cannula placed in the duodenum opposite the common ampulla of Vater (Fig. 1). The common bile duct was transected within the duodenal wall, allowing for the flow of bile into the duodenum through the transected duct. The remaining part of the duct was ligated at the point where it joins the major pancreatic duct to form a single channel entering the duodenum through the common ampulla. The animals were also provided with three small Thomas-type cannulas (Fig. 1), of which one was placed in the upper jejunum about $25 \mathrm{~cm}$ distal to the ligament of Treitz, the second in the distal jejunum about $50 \mathrm{~cm}$ distal to the ligament of Treitz, and the third in the ileum about $25 \mathrm{~cm}$ proximal to the caecum.

SECRETORY PROCEDURE The secretory tests were started about two weeks after the cats had recovered from surgery.

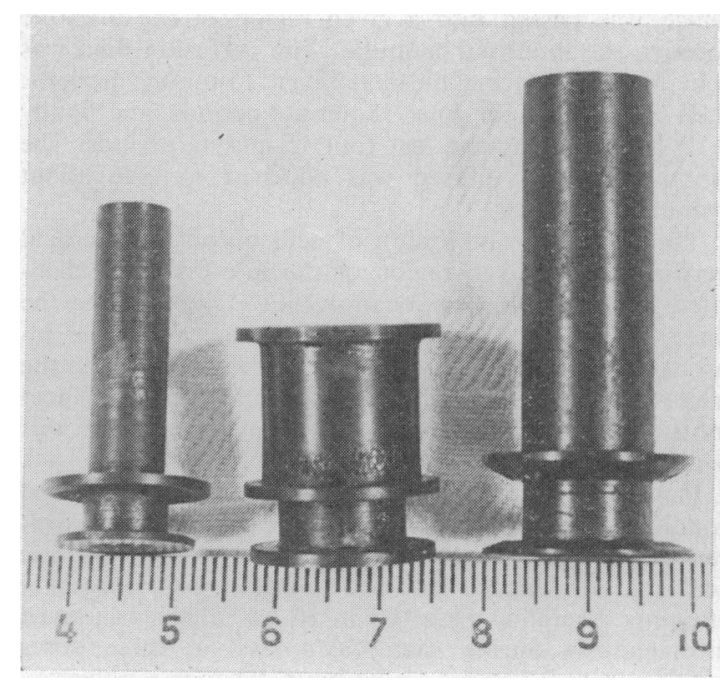

FIG. 1. The different types of cannula used in the study: left, intestinal cannula; middle, duodenal cannula; and right, gastric cannula. 
Gastric juice was collected into the graduated tubes by opening the gastric fistulas. Pancreatic juice was collected in the following manner. The duodenal fistula was opened and a polyethylene tube, $1 \mathrm{~mm}$ external diameter, was inserted through the ampulla about $6 \mathrm{~cm}$ into the major pancreatic duct and brought out through a small hole in the cork placed in the duodenal cannula.

At least two basal 15-minute collections of gastric and pancreatic juice were made each time to determine the fasting level of gastric or pancreatic secretion. If food was present in the stomach, or a high level of gastric acid secretion was found, the experiment was not carried out that day. The tests were made on the same animals no more than three times a week.

The acidity of gastric juice was determined by titration of $0.2 \mathrm{ml}$ samples to $p \mathrm{H} 7.0$ using $0.1 \mathrm{~N} \mathrm{NaOH}$ with an autoburet titrator ${ }^{1}$. Acid output was expressed in milliequivalents per 15 minutes.

The concentration of bicarbonate in pancreatic juice was estimated in $0.5 \mathrm{ml}$ samples by adding $1.0 \mathrm{ml}$ of $0 \cdot 1 \mathrm{~N} \mathrm{HCl}$. The mixture was briefly boiled, cooled to room temperature, and the residual acid was titrated to $p \mathrm{H} 7 \cdot 0$ using $0 \cdot 1 \mathrm{NaOH}$ (autoburet). The output of bicarbonate was expressed in m-equiv/15 minutes or per hour.

TEST PROCEDURE Gastric acid secretion was examined under basal conditions and after the intravenous infusion of a constant dose of either histamine dihydrochloride (80 $\mu \mathrm{g} / \mathrm{kg} /$ hour) or pentagastrin $(8 \mu \mathrm{g} / \mathrm{kg} / \mathrm{hour}$ ), using a peristaltic pump ${ }^{2}$. These doses had been shown previously on the same animals to induce near maximal gastric acid secretion. Throughout each experiment one level of the intestine was perfused from a peristaltic pump at a constant rate of 20 to $40 \mathrm{ml}$ per hour. Irrigation was performed with a plastic tube, $1.5 \mathrm{~mm}$ external diameter, which was passed into a given region of the intestine through the intestinal cannulas. The perfusion fluid was $0.15 \mathrm{M} \mathrm{NaCl}$ during the first seven 15 -minute periods, then $0.1 \mathrm{~N} \mathrm{HCl}$ for four 15-minute periods, and finally $0.15 \mathrm{M} \mathrm{NaCl}$ for the last four 15-minute periods. The amount of acid infused was adjusted to give about $1 \mathrm{~m}$-equiv/kg/hour.

The percentage inhibition of acid output during acid perfusion of a given region of the intestine was calculated for each test. The mean output of acid during the three 15-minute periods immediately preceding the infusion of acid solution was taken as the control, and the mean output during the next 15-minute periods of acid infusion was expressed as a percentage change from this control rate.

Pancreatic secretion was examined under basal conditions and in response to graded doses of intravenously infused synthetic secretin ${ }^{3}$ or to hydrochloric acid solution infused into the duodenum in increasing amounts. Secretin, dissolved in $10 \mathrm{ml}$ saline, was given intravenously during each day's tests in three doses ranging from 0.2 to $6.4 \mu \mathrm{g} / \mathrm{kg} /$ hour, through a polyethy-

${ }^{1}$ Radiometer, Copenhagen, Denmark.

'Unipan.

'Squibb Institute for Medical Research, New Brunswick, New Jersey batch number SQ 18773, ES XXX 126. lene tube inserted in the leg vein. In tests, both with secretin and intraduodenal acid, pancreatic dose responses for volume and bicarbonate output were calculated from the highest 15-minute volume or bicarbonate output multiplied by 4 . Hydrochloric acid diluted with distilled water to give the desired concentration was infused intraduodenally through a plastic tube at the rate of about $40 \mathrm{ml}$ per hour. The concentration of acid infused was doubled every 60 minutes and the infusion rate ranged from 0.25 to $2.0 \mathrm{~m}$-equiv acid $/ \mathrm{kg} / \mathrm{hour}$ during the same experiment. A small amount of phenol red $(200 \mathrm{mg} / \mathrm{l}$.) was added to the acid solution and the gastric juice drained from the gastric fistula was observed when titrated to $p H$ 7.0 for the presence of a red colour. No trace of this marker was found in the gastric collection, indicating that the infused acid solution did not escape back up through the pylorus.

After the dose response curve to intravenous secretin or intraduodenal acid infusion was obtained the amount of acid causing the highest pancreatic secretion was selected and infused in one day's test into a given region of the small intestine. Pancreatic juice was collected according to the method described above for one hour during the intraintestinal infusion of saline and then during one hour when acid solution instead of saline was infused into a given level of the intestine. The peak 15-minute volume and bicarbonate output during acid infusion multiplied by 4 was considered in the comparison of the effects of the acidification of various regions of the small intestine on pancreatic secretion.

Throughout pancreatic secretion, the gastric fistula was opened and the gastric juice drained to the exterior to prevent gastric acid from entering the duodenum. Acid concentration was determined in gastric collections and little or none was found in gastric juice. The results for gastric secretion are not presented.

\section{RESULTS}

PANCREATIC DOSE-RESPONSE CURVE TO INTRADUODENAL ACID AND INTRAVENOUS SECRETIN The intravenous infusion of synthetic secretin in single, graded doses induced a dose-related secretory response achieving the maximal level at the dose of $3.2 \mu / \mathrm{kg} /$ hour in all tests. Doubling this dose did not result in a further increase in volume of pancreatic secretion or bicarbonate output (Fig. 2).

As shown in Fig. 2, flow of pancreatic secretion and bicarbonate output were also related to the amount of acid infused into the duodenum achieving the maximal rate in all animals at 1.0 m-equiv acid/ $/ \mathbf{k g} /$ hour. This amount of acid was then used in the next experiments to compare the effect on pancreatic secretion of acid infusion in the successive levels of the small intestine.

EFFECT OF ACID INFUSION INTO VARIOUS REGIONS OF THE SMALL INTESTINE ON PANCREATIC SECRETION The highest volume of pancreatic secretion and 

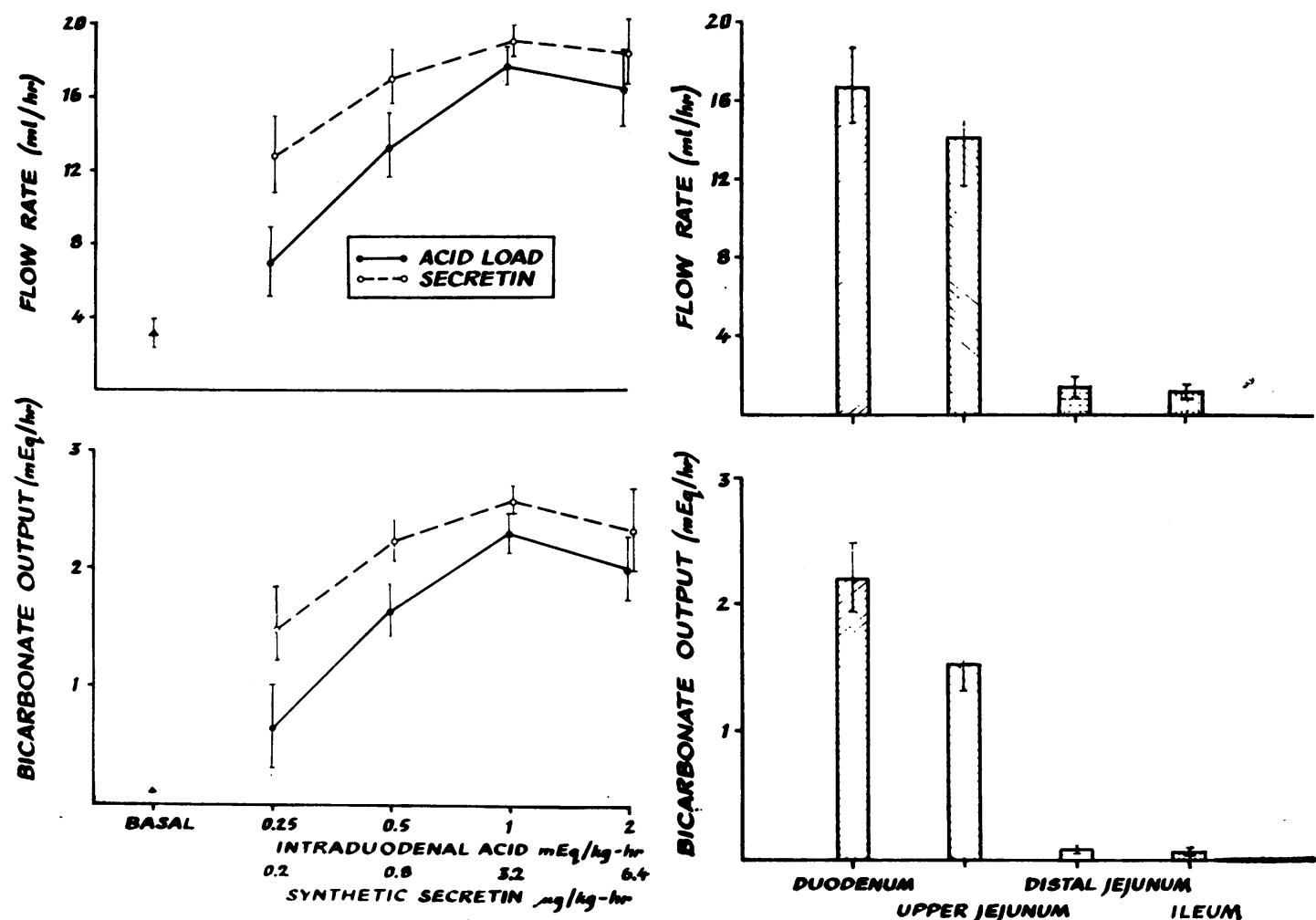

FIG. 2 .

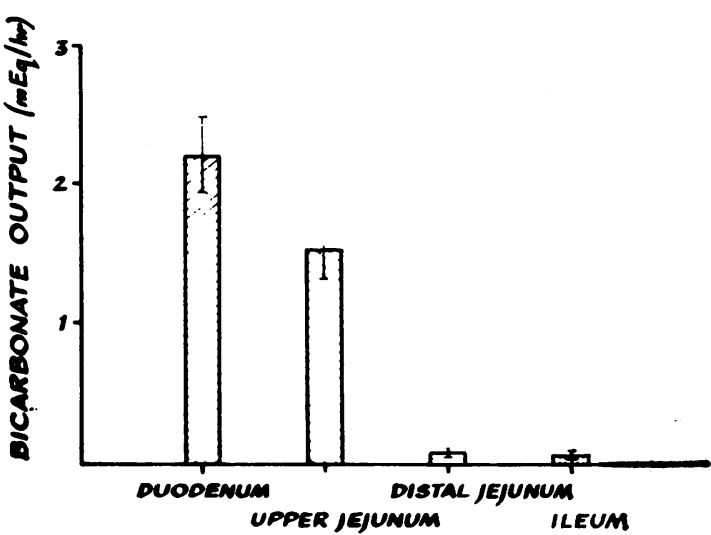

FIG 3.

FIG. 2. Pancreatic volume flow and bicarbonate output after intraduodenal infusion of increasing amounts of $\mathrm{HCl}$ or after infusion of synthetic secretin in increasing doses. Each curve is a mean of two experiments on each of five cats with gastric fistula opened.

In this and subsequent figures the vertical bars indicate the standard error of the mean.

FIG. 3. Pancreatic flow rate and bicarbonate output after the infusion of acid amounts of 1 m-equiv/kg/hour into different regions of the intestines. Mean of two experiments on each of five cats.

bicarbonate output were attained by intraduodenal acid infusion in amounts of $1 \mathrm{~m}$-equiv $/ \mathrm{kg} / \mathrm{hour}$, reaching about $90 \%$ of the maximum achieved by intravenous administration by synthetic secretin. The stimulation of pancreatic secretion was also obtained during acid infusion into the upper jejunum. In this instance the peak volume was about $80 \%$ and peak bicarbonate output was about $70 \%$ of that obtained with intraduodenal acid infusion. No change in pancreatic secretion was seen during the acidification of the distal jejunum or ileum (Fig. 3).

EFFECT OF ACID INFUSION INTO VARIOUS LEVELS OF THE INTESTINE ON PENTAGASTRIN- AND HISTAMINEINDUCED GASTRIC ACID SECRETION Pentagastrininduced gastric acid secretion was depressed significantly only during intraduodenal acid infusion. The inhibition of acid secretion reached about $50 \%$ of the control level (Fig. 4). Acid in- fusion into the upper jejunum caused an initial small decrease in the gastric acid secretion stimulated by pentagastrin, which then showed a slight tendency to increase. Acid irrigation of the distal jejunum or ileum did not result in any change in pentagastrin-induced gastric acid secretion, which showed a tendency to decline during the experiment. Histamire-induced gastric acid secretion remained unchanged by acid perfusion of the duodenum or other parts of the intestine (Fig. 5).

\section{DISCUSSION}

These data indicate that endogenous release of secretin by acid is confined to the duodenum and upper jejunum and that pentagastrin-induced gastric acid secretion is inhibited in the cat only after the acidification of the duodenum.

The distribution of secretin in the intestine has 

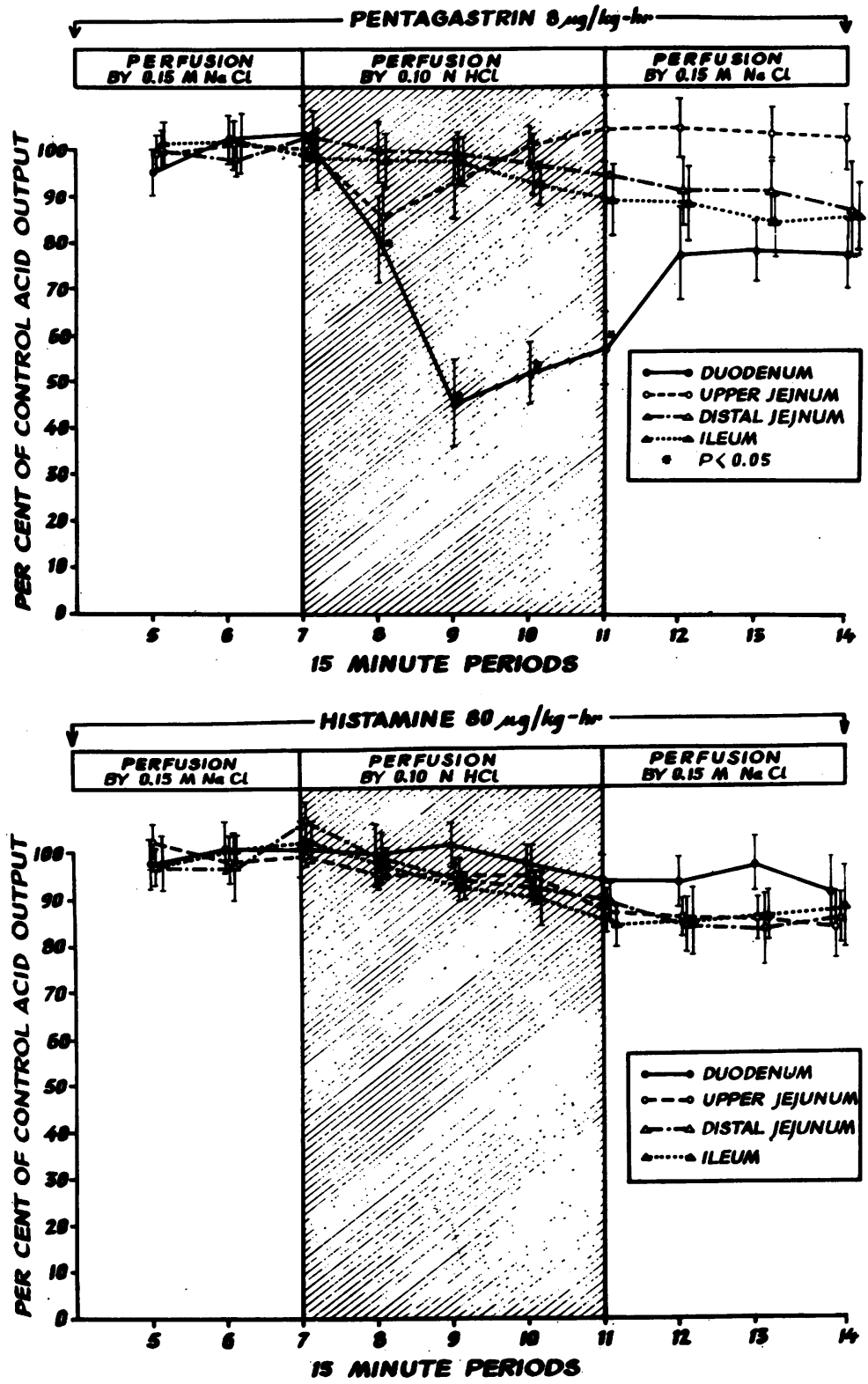

FIG. 4. Effect of acid perfusion at different levels of the intestine on pentagastrininduced gastric acid secretion in gastric fistula cats. Each curve is a mean of two experiments on each of five cats.
FIG. 5. Effect of acid perfusion at different levels of the intestine on histamine-induced gastric acid secretion in gastric fistula cats. Each curve is a mean of two experiments on each of five cats. been previously studied by Mellanby (1926), who found that in cats, unlike other species, secretin can be extracted only from the duodenal mucosa. To our knowledge no study has been undertaken to localize the endogenous release of secretin in the cat by acid infusion into different regions of the intestine. We have demonstrated that the area in which secretin can be released by acid irrigation in the cat extends to the upper jejunum. It was found that jejunal acidification resulted in a somewhat lesser pancreatic stimulation than that observed during the acidification of the duodenum.

It is of interest that acid infused into the upper jejunum did not inhibit the pentagastrin-induced gastric acid secretion seen during acid infusion into the duodenum. This might be attributed to a relatively smaller endogenous release of secretin by acid in the jejunum as compared with that in the duodenum. In contrast to the almost complete inhibition of gastrin-induced gastric secretion 
in the dog (Johnson and Grossman, 1968) by acid irrigation of the duodenum, we observed only about $50 \%$ inhibition of pentagastrin-induced gastric secretion in the cat. This agrees with our previous report (Konturek, 1968), showing that in the cat gastric secretion stimulated by pentagastrin is more resistant to inhibition by intraduodenal acid or intravenous secretin.

Among several agents releasing secretin from the intestinal mucosa and stimulating pancreatic secretion, hydrochloric acid was recognized over a century ago (Leuret and Lassaigne, 1825; Dolinski, $1894)$ as the most effective. The efficiency of hydrochloric acid in stimulating pancreatic secretion was not properly evaluated before highly purified secretin preparations were available (Ondetti, Sheehan, and Bodanszky, 1967).

Our present study demonstrates that the maximal pancreatic secretion achieved by exogenous synthetic secretin was only slighter higher than that obtained with intraduodenal acid infusion. The difference in the stimulation of the pancreatic secretion induced by exogenous secretin, and secretin released endogenously by acid in the duodenum, might be attributed to the acid perfusion of the middle and distal parts of the duodenum, which were shown to contain a smaller amount of secretin than the upper part (Mellanby and Huggett, 1926).

\section{REFERENCES}

Dolinski, I. L. (1894). On the Influence of acids on the secretion of pancreatic juice. (Russian) Thesis St Petersburg. Quoted by B. P. Babkin (1950). Secretory Mechanism of the Digestive Gland. 2nd ed. Hoeber, New York.

Johnson, L. R., and Grossman, M. I. (1968). Secretin: the enterogastrone released by acid in the duodenum. Amer. J. Physiol., 215, 885-888.

Konturek, S. J. (1968). The effect of secretin on gastric acid secretion and peptic ulcers induced by pentagastrin in cats with intact or resected duodenum. Amer. J. dig. Dis., 13, 874-881.

- Dubiel, J., and Gabryś, B. (1969). Effect of exclusion, acidification, and excision of the duodenum on gastric acid secretion and the production of pentagastrin-induced peptic ulcers in cats. Gastroenterology, 56, 703-710.

_, Gabryś, B., and Dubiel, J. (1969). The effect of exogenous and endogenous secretin on gastric and pancreatic secretion. Amer.J. Physiol., in press.

on $\mathrm{HCl}$ secretion in man and in cats with gastric fistulas and Heidenhain pouches. Gastroenterologia (Basel), 106, 281-294.

Leuret, F., and Lassaigne, J. L. (1825). Recherches Physiologique et Chimiques pour Servir à l'Histoire de la digestion, pp. 141. Huzard, Paris.

Mellanby, J. (1926). The secretion of pancreatic juice. J. Physiol. (Lond.), 61, 419-435.

- , and Huggett, A. St. G. (1926). The relation of secretin formation to the entrance of acid chyme into the small intestine: the properties of secretin. Ibid., 61, 122-130.

Ondetti, M., Sheehan, J. T., and Bodanszky, M. (1967). Synthesis of gastrointestinal hormones. In International Symposium on the Pharmacology of Hormonal Polypetides and Proteins. Plenum, New York, in press. 